\title{
Energy efficiency learning and practice in housing for youths
}

\author{
Wiktoria Glad ${ }^{1 *}$, Josefin Thoresson ${ }^{2}$ \\ ${ }^{1}$ Department of Thematic Studies, Linköping University, Linköping, Sweden \\ ${ }^{2}$ Department of Thematic Studies, Linköping University, Linköping, Sweden \\ *Corresponding author. Tel: +46 13282259,E-mail: wiktoria.glad@liu.se
}

\begin{abstract}
This paper explores the energy efficiency learning and practices of youths aged 18-25 years. The studied youths are involved in a project, initiated by a municipally owned housing company, to educate residents and change everyday behaviour, making it more sustainable and energy efficient. This project, which forms our case study, covers socio-technical features such as energy systems and the individual metering and billing of heating, electricity, and hot and cold water. How did the youths perceive and use the systems? Have their attitudes and behaviours concerning energy-related practices changed during the project? The results indicate that a combination of technology (e.g. metering and visualized energy use) and social activities (e.g. educational activities and meeting neighbours and housing company staff) changed some practices involving what was perceived as energy wasting behaviour (e.g. using stand-by modes and taking long hot showers), while other practices (e.g. travelling and heating) were harder to change due to socio-technical barriers. The youths displayed knowledge gaps in relation to the energy system and their basic understanding of energy (the difference between heating and electricity).
\end{abstract}

Keywords: Everyday life, youths, housing, socio-technical systems

\section{Introduction}

A common notion is that children and youths represent our future hope in terms of changing unsustainable behaviour. Sustainability is now integrated into Swedish pre-school and primary school curricula and covered in secondary school and university courses. Environmental awareness might also be important in working life, for example, if an employer is involved in an environmental certification scheme. However, for most people, learning about sustainability and, for example, energy conservation and low-energy lifestyles is not included in their everyday activities. As an adult, education is voluntary, and it can be assumed that few people intentionally seek a deeper understanding of environmental issues. Many are exposed to information from various sources, such as their energy supply company or local municipal energy advisors. However, mere information provision is considered a soft and perhaps weak policy means, and research finds that it has little or no effect on behaviour [1], while learning can reach deeper into people's values and might even change behaviour [2-4]. One key difference between learning and information provision is that learners receive feedback on their thoughts and actions, as learning often involves communicating with other people (possibly using various information and communication technology tools) [1]. Information provision is one-way and, by definition, is not communication at all. Published research into intervention and energy conservation behaviour is mostly found in the areas of psychology and social psychology [1,5-7], while the present research focuses on another level of behaviour, namely, socio-cultural and socio-technical behaviour; consequently, we chose learning and practice as our central areas of research [8-13].

The starting point of this research was to explore the learning of youths and young adults in an after-school setting outside conventional formal learning facilities. Specifically, we examine learning about sustainable energy-use behaviour and energy conservation in the homes of 18-25-year-olds. We use a qualitative case study methodology, the overarching aim of which is to understand energy learning among youths and young adults in a project targeting energy conservation attitudes and behaviour. The main objectives are to explore 
stated energy-use behaviour from the end-user perspective and to assess the success or failure of a project aiming to change behaviour through learning. We would also like to suggest ideas for improving the learning approach that may be useful to stakeholders and policy-makers.

\section{Theory and methodology}

The analyses presented here will be based on our understanding of social learning; this concept stems from research into the learning in action approach [14] and practice theory [15]. Under certain circumstances, knowledge can be assimilated by an individual and put into action, possibly leading to change [16]. Liedman [17] stresses that knowledge must be put in $a$ wider context and be put to the test. This is also the basis of Säljö's situated learning approach [14], according to which learning is not a harmonious occurrence but the result of individual struggle and commitment, hence, a process. Practice theory takes a similar approach to understanding human action, which is seen as resulting from a combination of structural prerequisites and individual and social processes. Instead of making situations the centre of analysis, Gram-Hanssen [8] emphasizes people's practices and activities when performing everyday tasks. We take this approach here, starting our analysis with how the studied youths and young adults do things. Practices are complex phenomena and can extend outwards from the home or the places where they usually occur. Gram-Hansen quotes Schatzki when defining practices as our "doings and sayings" [15]. Gram-Hansen has developed Schatzki's theories by introducing physical features and technology, making the approach more socio-technical.

Given the qualitative approach of this research and our aim of understanding a sociotechnical phenomenon, case study methodology is suitable. Case study research focuses on real-life phenomena, and the inclusion of various contexts is encouraged when relevant [18]. Qualitative research aims at making detailed descriptions and creating in-depth understanding of phenomena. The boundaries of a case study can either be well defined in advance [19] or gradually be defined during the research [20]. The present research is a small case study based in a well-defined geographical area, the Ringdansen development, but the boundaries of the examined social learning extend beyond the neighbourhood.

The case study focuses on the "Youth Housing" project in the Ringdansen development in the town of Norrköping, Sweden. Since 2008, Linköping University has collaborated with the owner of this development, Hyresbostäder i Norrköping AB (HNAB), a housing company owned by Norrköping municipality. In 2009, HNAB initiated a project to attract a "new group" of tenants to the Ringdansen neighbourhood and enhance its green profile. The concept and organization of the project were not created in collaboration with Linköping University but were HNAB's own initiative and design; the collaboration merely gave Linköping University researchers easy access to the neighbourhood. HNAB has recently been promoting Ringdansen using the Climate-Clever Living programme, and a new logo has been launched. The programme offered a 50\% rent discount to people aged 18-25 years, who could earn two-year leases for two- or three-bedroom flats in one of the residential buildings. To earn a lease (20 in total), one had to commit to involvement in a programme including various activities, for example, meetings and practical outdoor actions such as picking up litter in a recreational area near the neighbourhood. The meetings the housing company organized for the youths typically included a presentation on an environmental issue, such as global warming or global food consumption, supported by a movie or guest lecturer, followed by discussion of practical actions for reducing one's environmental impact, as related to the issue presented. The meetings were independent of each other and entailed no homework or reflections between the meetings. It was our initiative to ask permission to evaluate the project after one year. 
Various data collection techniques can be used with case study methodology [18]; for our objectives, however, we chose to conduct focus group interviews. Focus group interviews produce primary data on the thoughts and understandings of people talking with each other in the same situation [21,22]. In the focus groups for the present research, we concentrated on issues related to energy and the environment. The analyses of interviews are our own; the results of the analyses were presented to housing company representatives, who gave us feedback on them. Since only 20 households participated in the Youth Housing project, yielding a small number of possible respondents, we invited all members of these households to attend the focus groups. Fifteen household members participated, representing almost 50\% of the total, comprising nine women and six men. Four focus groups were organized by two researchers, one responsible for recording the interviews and taking notes and the other for keeping the conversation going and introducing new topics when the current topic seemed to be exhausted. The topics were presented using six pictures depicting the neighbourhood, energy, and the housing company. The youths responded to and understood what the pictures visualized in quite similar ways, even though divergent practices were related to the pictures during discussion; these results will be presented in the next section. The interviews were digitally recorded and transcribed, resulting in 50 pages of text. The relatively small amount of text made it possible to manually organize the primary data into various themes in accordance with the energy and environmental focus of the research project. The analyses were inspired by the hermeneutic research tradition and the hermeneutic circle [23]. There is always a risk of "going native" relative to the object of study and when interpreting the results. However, the researchers did not participate in conceiving or organizing the "Youth Housing" project and had no vested interests in whether or not the results of the project could be considered fulfilled.

\section{Results}

The results of the focus group interviews can be organized into three themes: stated behaviour in relation to heating, stated behaviour in relation to electricity and stated behaviour in relation to the individual metering and billing system (IMB) of the Ringdansen neighbourhood.

\subsection{Stated behavior in relation to heating}

Chilliness and technical issues were central when the youths talked about their behaviour in relation to heating. All apartments are equipped with a thermostat for temperature control device which should allow occupants to set indoor temperatures of $18-22^{\circ} \mathrm{C}$ and each flat pays individually for its use of heath. However, most youths found the indoor temperature too cold, with the thermostat set at its highest level, compared with earlier living experiences and with what they were used to in earlier homes (this was the youths' own impressions and does not reflect measured values). A common observation was that the insulation performance was inadequate due to a design flaw concerning the windows. One interviewee thought that the sealing around the windows was not good enough, and many youths experienced air ingress around windows and draughty flats. All flats are equipped with a ventilation outlet under the windows and many youths created their own solutions to prevent cold air coming into the flats through these outlets, for example, by using towels to block the ventilation outlet to raise the indoor temperature. Another practice was to put on slippers and more clothes if the indoor temperature was perceived as too cold. One interviewee claimed that it was unnecessary always to turn up the thermostat and said "If it is cold indoors, I put on my slippers and a cardigan”. That was a common practice for many youths, said that the fear of higher energy bills was their main motivation. For some people, environmental factors such as melting polar icecaps and dying polar bears were important reasons for not using more energy than 
needed. One youth claimed that these issues could be difficult to understand, but said: "I think that we here (i.e. in the Youth Housing project) can learn from each other”.

Many youths struggled to learn how to use the thermostat as a temperature control device and it was described both as a tool for heating control and as a tool that simply did not work.

Respondent 1: I thought that it (i.e. the thermostat) would be better than it was. I thought that it was pretty cool to have a thermostat indoors, only because I've seen them on TV but later I was ...

Respondent 2: Always in American movies.

Respondent 1: Yes, everybody has a thermostat as a temperature-control device, and they can lower their thermostat because it is often very warm inside. But we have more like ...

Respondent 2: Raise the thermostat because it is so cold.

Respondent 1: Yes it is like that here.

Some perceived the thermostat, as a temperature control device, as difficult to understand and as a barrier to controlling the indoor temperature. One youth said that it was strange that you could not simply set the thermostat to the temperature you wanted indoors (the thermostat was not marked with numbers). Some thought that the thermostats should function differently, and others did not like the thermostats at all because they were difficult to understand ("I do not like it at all"). Some youths described the thermostats as a tool for deciding how much heat to use in the flat, saying that it was a useful innovation since everybody had to pay for their own energy use. A common practice among many youths was to lower the thermostat in daytime and then raise it in the evenings. It was also common to turn off the heating system in summer, since it was usually not needed then. Youths with small children said it was a difficult decision to turn off the heat, since the children needed a warmer indoor temperature.

\subsection{Stated behaviour in relation to electricity}

The difference between heat and electricity was not obvious to all the youths. During discussions about the thermostat, it turned out that many had a knowledge gap regarding how their flats were heated, and one youth did not distinguish between electricity and heating consumption, even though the flats were heated with district heating and not with electricity. The thermostat technology was a barrier to a few who equated the thermostat with both temperature control and electricity, assuming that if the thermostat was turned off, the electricity to the flat would be cut, which was not the case. One also assumed that the level on the thermostat would affect the electricity bill, and was afraid of receiving higher electricity bills if the thermostat was set too high. All youths, however, said it was important to save electricity because this affects the global environment and can reduce the greenhouse effect.

Trying to reduce the amount of electricity used was an ongoing process in many households. A common energy-saving practice that many were using was turning off electrical appliances when not in use and not simply leaving them in stand-by mode. As one youth put it:

We always unplug all the cords for our electrical appliances, like all lamps, the TV, the microwave, for everything. The cords have to be unplugged.

Interviewees said that it was easy to forget to unplug cords and turn off appliances when unused, although many said that they tried remember. One respondent said that, before the household had moved to the neighbourhood they seldom turned off the TV when they went to bed, now, however, they always turned it off. Another respondent claimed that the computer was always left on before, even though no one was using it. The move to the youth living project had changed that, and nowadays the household always turns off the computer when not in use. Most respondents found that it easy to remember to save electricity when they first 
moved into the neighbourhood, though many remarked that it was easy to forget about electricity use in everyday life. Similar studies have noted the same phenomenon (24).

Respondent 7: You forget. It is so easy to forget.

Respondent 8: I thought about it a lot at the beginning, but I can say that now I am a bit careless about it.

During the focus group interviews, energy were also connected to travelling and small-scale energy production, which some youths wished was installed in the neighbourhood. Many youths used cars for transportation but not all households had access to a car, so many used the bus or bicycle for everyday transportation. The bus was said to be slow, and it was sometimes faster to ride a bicycle instead of taking the bus to the city centre. Many youths had great hopes that the housing company would embark on small-scale energy production, and expected leading-edge energy-production innovations and energy-efficient technology to be implemented in the neighbourhood. The youths described the housing company in mostly positive terms. They appreciated its accessibility and the meetings it organised in the Youth Housing project, though some wanted more concrete action from the housing company.

Respondent 3: It is the next step. For now they try to engage people. The next step is ... Respondent 4: Action.

\subsection{Stated behaviour in relation to individual metering and visualization}

The system for individual metering and billing was appreciated by most youths. The ability to influence the costs by paying for the rent and energy use separately was regarded as an advantage of the Youth Housing project, since it is seldom the case in Sweden. One youth said individual metering and billing was the best thing about the Youth Housing project. Many thought that this system was environmentally friendly, since it makes individuals start thinking about the energy they use, as they have to pay for it themselves. By making it obvious that energy has a cost, the system almost challenges individuals to save energy:

It is good, especially from an environment perspective, and I think that you should not use more than you need. That is important.

When the bill came every month the system visualized the energy used in numbers and kilowatts, although many were vague as to what a kilowatt really represented or how it was measured. Understanding the energy consumption data on the bill or how the system worked was not considered that important. Feedback systems have been used in earlier studies with varying results, frequent feedback being found most effective [1]. In the present case, the energy bill functioned almost like a feedback system, giving feedback every month on energy used in terms of how much money the youths had to pay. Saving energy was often equated to saving money, since lower electricity use results in a lower electricity bill. Households would even compete against themselves, by trying to get lower electricity bills every month. They would think back over their energy behaviour in the current month versus in earlier months, and try to learn what to do or not to do the next month. The incentive to save money was a frequently citied reason, since many households were low-income or student households.

Trust in system's features and functions was high among the youths. No one doubted that their bill accurately recorded their energy use, but assumed that the technological system was working as it was supposed to, although it is always possible for technical systems to have flaws. The youths could not really determine by themselves whether the metering system was working as intended, and it was not usual to compare one's energy used with one's neighbours'. Social activities initiated by the housing company helped influence resident 
attitudes and were appreciated. One youth said that before he did not think his use could make a difference. After he moved to the neighbourhood, however, he changed his mind:

I think that involvement with the other youths in the block affects my consciousness and has made me more aware of the importance of everybody doing something when it comes to energy saving.

\section{Discussion}

Results indicate that a combination of technology (i.e. metering and visualized energy use) and social activities initiated by the housing company (e.g. educational activities and meeting neighbours and housing company staff) changed some of the practices involved in what were perceived as energy-wasting behaviour (e.g. using stand-by modes and taking long hot showers), though other practices (e.g. transportation and heating) were more difficult to change due to socio-technical barriers. Learning related to the home and various household activities might, according to the theories of situated learning [14] and practices [15], be the right approach to altering unsustainable behaviour, shifting it in the direction of low-energy living. The housing company is on the right track in choosing a learning approach for their Climate-Clever Living project. However, regarding the Youth Housing project, few respondents referred to specific things they had learnt in the first year of the project. Instead, reference was made to the fellowship between young residents of the neighbourhood. Most respondents, however, approved of the housing company's ability to inform them of energy and climate issues. Over the course of the year the project had run, the housing company had earned the youths' trust when it came to environmental matters [25].

Learning as a struggle [14] to become more knowledgeable was not acknowledged to any great extent by either the housing company or its tenants. The struggle mostly involved learning how to use devices, such as a thermostat, in the meetings, not learning and retaining changed behaviour, for which information provision alone has been demonstrated to be insufficient [1]. No pressure was put on the youths to reflect on or analyse their behaviour. Formal learning usually involves homework and studying for tests; in this project, however, learning was supposed to take place in the homes of the tenants and in the interaction with other tenants and the housing company. As a result, changing basic practices at home was never discussed in depth, and some youths went back to their former and less-energy-efficient modes of behaviour - as exemplified when they talked about saving electricity. Instead, the youths emphasized new, more innovative initiatives and a desire for the housing company to take action, rather than emphasizing how to do one's laundry in an energy-efficient way or manage the temperature of one's flat. The more innovative ideas included bicycle pools, second-hand clothing businesses, and solar panel and PV installation. Ongoing reflection on current practices and struggle to change one's behaviour may not be fun, but are necessary in order to change behaviour.

Putting new knowledge in a wider context is also crucial in efforts to create change [17]. It might be difficult to recognize the relationship between individual energy consumption and environmental problems [26] - although this was not a problem here - so context is always important. The contexts made available in the project were either the neighbourhood of Ringdansen or the other extreme, the globe. The neighbourhood might be too narrow a context in which to fully understand a new behaviour, while the globe might be too overwhelmingly large to relate to. Here, learners need help navigating through various contexts and must be shown how a behavioural change might influence contexts at various scales, i.e. the household, building, neighbourhood, precinct, town, region, country, continent, and globe. It was possible for the youths to compare their energy use with their neighbours', 
but they said they seldom did that. We suggest that the data collected through the IMB system be used to set household behaviour in a wider context and make it possible to compare individual efforts with those of the entire neighbourhood and at other geographical levels.

\section{Conclusions}

An overall conclusion is that the project was successful in terms of changing some attitudes and energy-related behaviour. However, the youths displayed knowledge gaps in relation to the energy system and their basic understanding of the installed energy systems (e.g. the difference between the heating and electricity systems). Learning as a process must be acknowledged and the difference between providing and obtaining information, and learning and assimilating knowledge must be recognized when designing change-creation projects and schemes. Learning is an ongoing process that differs between individuals. Consequently, changing behaviour is better approached as a scheme than a project.

Learning includes socio-technical features. To facilitate learning and change, it is essential to provide infrastructure so that learning can take place in a wide range of places and not be restricted to certain, special places. In this case, HNAB has provided some state-of-the-art technical infrastructure, such as individual metering and billing. However, the infrastructure might also be social networks and include, as in this case, neighbours or even professionals from the housing company. These networks can give rise to more formal support groups than those existing between some youths, either in person or via the Internet. Technology has great potential as a tool for change, but that potential is underused in Ringdansen. We should not be afraid to approach learning about low-energy living in a fun way, making use of residents' creative ideas, like those of the studied youths.

For HNAB and perhaps other housing companies in Sweden, our results suggest that the present model of education for youths might be made more accurate and more flexible. It might be too challenging to target all groups of tenants at the same time, but starting with "easy" groups that are already somewhat interested in environmental issues is definitely the right way to proceed. The next group to target might be senior tenants, for example. According to a survey conducted in Ringdansen, the housing company is perceived as trustworthy by youths and young adults, so HNAB representatives should be the ones presenting data and discussing environmental issues with tenants. However, it is crucial to focus more on facts and data about a range of environmental issues and then provide opportunities to reflect on and discuss the information given. We would like to see a more comprehensive model of how the housing company will work on change creation in the future.

\section{References}

[1] W. Abrahamse, L. Steg, C. Vlek, \& T. Rothengatter, A review of intervention studies aimed at household energy conservation, Journal of Environmental Psychology 25, 2005, pp. 273-291.

[2] L. S. Vygotskij, Mind in society: the development of higher psychological processes, Harvard University Press, 1978.

[3] A. Bandura, Social learning theory, Prentice Hall, 1977.

[4] M. S. Reed, A. C. Evely, G. Cundill, I. Fazey, J. Glass, A. Laing, J. Newig, B. Parrish, C. Prell, C. Raymond, \& L. C. Stringer, What is social learning? Ecology and Society 15, 2010, online. 
[5] W. O’Dwyer, F. Leeming, M. Cober, B. Porter, \& J. M. Jackson, Critical review of behavioural intervention to preserve the environment: research since the 1980s, Environment and Behaviour 25, 1993, pp. 275-321.

[6] T. Jackson, Motivating sustainable consumption: a review of evidence on consumer behaviour and behavioural change, Energy Environment 15, 2005, pp. 1027-1051.

[7] L. Steg \& C. Vlek, Encouraging pro-environmental behaviour: an integrative review and research agenda, Journal of Environmental Psychology 29, 2009, pp. 309-317.

[8] L. Lutzenhiser, Social and behavioural aspects of energy use, Annual Review of Energy and Environment 18, 1993, pp. 247-289.

[9] H. Wilhite, H. Nakagami, T. Masuda, Y. Yamaga, \& H. Haneda, A cross-cultural analysis of household energy use behaviour, Energy Policy 24, 1996, pp. 795-803.

[10]H. Wilhite, E. Shove, L. Lutzenhiser, \& W. Kempton, Twenty years of energy demand management: we know more about individual behaviour, but how much do we really know about demand, Proceedings of the ACEEE, 2000, pp. 8435-8453.

[11]A. Kollmuss \& J. Agyeman, Mind the gap: why do people act environmentally and what are the barriers? Environmental Education Research 8, 2002, pp. 239-260.

[12]E. Shove, Comfort, cleanliness and convenience, Berg Publishers, 2003.

[13]S. Moloney, R. E. Horne, \& J. Fien, Transitioning to low carbon communities - from behaviour change to systemic change, Energy Policy 38, 2010, pp. 7614-7623.

[14]R. Säljö, Lärande i praktiken: ett sociokulturellt perspektiv, Norstedts, First edition, 2005.

[15]K. Gram-Hanssen, Introducing and developing practice theory - towards a better understanding, in: K. Karlson \& K. Ellegård, eds., Proceedings of the sustaining everyday life conference, Linköping University Electronic Press, 2010, pp. 45-57.

[16]P. Wickenberg, Information, kunskap och lärande, Att handla rätt från början, Naturvårdsverket, 2001, pp. 159-171.

[17]S. Liedman , Ett oändligt äventyr: om människans kunskaper, Bonnier, 2001.

[18]R. K. Yin, Case study research: design and methods, SAGE, Second edition, 1994.

[19]S. B. Merriam, Qualitative research and case study applications, Jossey-Bass, 1998.

[20]C. C. Ragin \& H. S. Becker, What is a case? Exploring the foundation of social inquiry, Cambridge University Press, 1992.

[21]R. S. Barbour \& J. Kitzinger, Developing focus group research: politics, theory and practice, SAGE, 1999.

[22]D. L. Morgan, Focus group kit. Vol. 1, The focus group guidebook, SAGE, 1999.

[23] J. Willis, Foundations of qualitative research: Interpretive and critical approaches, SAGE, 2007.

[24]E. S. Geller, Evaluating energy conservation programs: Is verbal report enough? Journal of Consumer Research 5, 1981, pp. 331-335.

[25]W. Glad \& J. Thoresson, Values, knowledge and behaviour - results of a survey, forthcoming.

[26]G. Brandon \& A. Lewis, Reducing household energy consumption: a qualitative and quantitative field study, Journal of Environmental Psychology 19, 1999, pp. 75-85. 